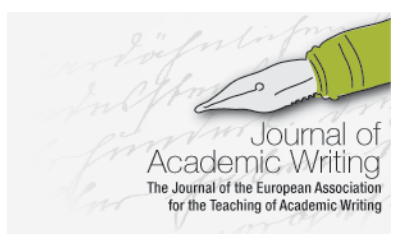

Journal of Academic Writing

Vol. 10 No 1 WINTER 2020, pages 146-153 https://doi.org/10.18552/joaw.v10i1.593

\title{
Digitalization and the Writing Classroom: A Reflection on Classroom Practices
}

\author{
Crystal Bickford \\ Southern New Hampshire University, USA
}

\begin{abstract}
This paper outlines the educational benefits of creating digital stories for a variety of academic purposes as well as the professional need for students to develop and showcase digital proficiency. Digital stories fall under the category of multimodal composition and new media studies, and they encourage students to expand their digital literacy skills while reconceptualizing ways in which traditional writing projects can appeal to a broader audience. The article also addresses some of the classroom challenges teachers may face when trying to implement the practice and some practical resources that might assist teachers to integrate digital stories into their classrooms.
\end{abstract}

\section{Introduction}

A conference presenter and her students outlined a compelling case for digital stories at an international conference. The presentation spoke to the varied topics students selected as well as the imaginative integration of images, video, music, and narration that culminated into engaging and thoughtful presentations. Intrigued, I returned home with a plan to implement similar projects. Although challenging at times, I am pleased with my decision to experiment within this genre. I take delight in the projects I have received - from originally-written rap songs to hand-drawn animations; however, there have been an equal number of lessons learned.

Primarily, I have noted that although students adeptly use video within social media platforms, they rarely understand basic hardware and software skills that extend social media boundaries. Likewise, students are reticent in incorporating personal identity into their work, and they struggle to to think about the ways in which visual meaning can extend the power of their written work. Working with multimodal composition for over ten years, I continue to challenge my students with the task of creating digital stories due to their depth and flexibility. This article outlines two different scenarios including students' failed opportunities to represent themselves as diverse individuals in a storytelling course and how digital stories, often thought to be better as creative pieces, offered ways of presenting research results in vibrant and exciting ways.

At their core, digital stories are 1-10 minute video productions consisting of still photos, video, music, and most often, narration by the student (Hull, 2003; Robin, 2016), and they encourage creators to develop content beyond the written word in ways that still uniquely address pathos, ethos, and logos. Digital stories are personal due to the author's control of the narrative and critical decision-making regarding their desired audience reactions.

\section{The Case for Digital Stories}

Digital stories are frequently touted as necessary to many college classrooms that seek to incorporate writing and audience-centered projects as learning objectives; digital stories enable students to increase their technical skills (Westman, 2012), articulate decision-making 
processes (Porter, 2006), and develop the ability to "speak to... reason and emotion" (McLellan, 2006, p. 28) while they incorporate strong research and writing skills (Robin, 2016). Dreon et al. (2011) use Ohler's work (2006) to point out that "the process of creating a digital story involves leveraging a wide variety of skills, including researching topics, writing scripts, storyboarding, and assembling the final product using video editing software" (Dreon et al., 2011, p. 5). There is a need for students to address the process of how content is created. For instance, outlining, storyboarding, script-writing, layout, and design features dovetail with the final message in ways that require critical thinking, creativity, information literacy, and technological dexterity. Thus, the academic content of the course remains emphasized throughout the creation process.

Academically, producing meaning that is task-based and linguistically oriented (Oskoz \& Elola, 2014) teaches students the "interdependent roles of visual, spatial, and auditory inputs in the construction of meaning" (Strassman \& O'Dell, 2012, p. 341). Students must address responsible meaning-making in ways that address audience, purpose, and ethical use of information. In my classes, additional activities often associated with writing endeavors were not only present, but enhanced. These include peer review/response, outlining, drafting, and reflection. The malleability of digital stories allows the activity to span across disciplines and to connect to other writing assignments as close to or as independently from course outcomes as an instructor chooses. As such, digital stories do not replace traditional research papers, which still provide students with a variety of academic and professional skills, but rather, digital stories can extend and broaden students' abilities to create and share knowledge.

At my institution, increased emphasis is being placed on career-readiness as opposed to providing students with a traditional university experience, and fostering digital skills is an essential component to work-place preparedness. Gilchrest (2018), specifically, examines the need for digital skills when he posits, "[m]any educators consider such skills essential to literacy in the information age. In the context of higher education, rhetoric and composition courses increasingly take on the responsibility of teaching future leaders to make effective and responsible use of multimodal compositions in their communication" (p. vi). Employers are actively seeking college graduates with proven computer skills. For instance, The United States Bureau of Statistics found that by $2020,77 \%$ of jobs will require technological literacy (Harris, 2017). A study conducted by Burning Glass Technologies ${ }^{\text {TM }}$ highlights other vital statistics, including that:

- $82 \%$ middle-skill (customer and operational side of businesses) jobs require digital skills.

- Digitally intensive middle-skill jobs pay more than non-digital middle-skill jobs.

- Digital skills provide a career pathway into middle- and high-skill jobs.

Additionally, digital and multimodal projects help support students who may otherwise be challenged by written texts. Students, especially visual learners, are now able to process how meaning is conveyed visually, which can help them when they return to writing. When students create "their own digital stories, [they] encounter an integrated instructional activity that requires them to leverage a host of cognitive, interpersonal, organizational and technical skills" (Dreon et al., 2011, p. 5); therefore, digital stories can reach students who commonly struggle with more traditional written assignments.

Arguably, creativity may or may not be a course objective; however, whether, as teachers, we see creativity as central to our classroom, it is an advantage which invites students to increase their engagement with an activity. When they have a deeper personal investment, they then problem-solve in ways they might not have otherwise considered. Simply put, "our students have a much richer imagination for what we might accomplish with the visual than our journals have yet to address" (George, 2002, p. 12). 


\section{Digital Natives}

However, for all the benefits digital stories provide, acknowledging the classroom population is equally important. When describing either the soon-to-be-graduating Millennial generation, or the current iGens, the phrase "digital native" is often one of several characteristics applied to them (Smith, 2012; Akcayir et al., 2016). Because they have never known life without computers, tablets, and sophisticated smartphones, their skills are often incorrectly correlated to our rapidly advancing technological society. It is easy to conflate students' abilities to negotiate apps to authentic competencies using sophisticated software and presentation design elements. As such, it is essential to address the vast perceptions of the term "digital native" in order to be able to determine just what our expectations of digital stories ought to be. In sum, digital native speaks more towards the general characteristics of our current students than offering one, clear-cut, universal definition.

Although "digital native" refers, broadly, to individuals born after 1980 (Prensky, 2004), the term is also often used to describe those who grew up in an age when they were submerged in many different forms of technology, most of which were advancing at a staggering rate. Others define digital natives as those with specific characteristics, such as a desire for speed in processing information, multitasking, and social learning (Prensky, 2001; Rosen, 2010). Still others interpret the term by a perceived set of technological skills, or the students' abilities to use different software packages extending beyond phone applications. Moreover, as Thompson (2013, p. 15) points out, regardless of how the term is defined, there is an overall perception that when educators fail to adopt technology use in the classroom, they are "failing the students by not adapting instruction to their needs."

It is easy for some of us to assume that because the current college student population has grown up with vast access to technology, they are proficient in the many variations technology now provides; however, we often learn that this is not the case (Smith, 2012; Bennet \& Maton, 2010). This is not to say that digital natives are devoid of technological skills, and more importantly, we should recognize that because technology is not foreign to them, they are positioned to embrace digital stories in other ways. Robin (2016) outlines common learner characteristics exhibited by current learners, including those who: 1) are technologically savvy, 2) rely on search engines for information, 3) have an interest in multimedia, 4) create internet content, 5) learn by inductive discovery, 6) learn by trial and error, 7) have short attention spans, 8) communicate visually, 9) are emotionally open, 10) feel a pressure to succeed, and 11) continuously seek feedback. The flexibility of digital stories, therefore, provides profound opportunities to apply their inherent skills while learning advanced digital literacy competencies and presenting their own unique and individual styles; however specific care for implementation must occur.

\section{The Tale of Two Classes}

As described below in the two experiences I selected for the article's discussion, there are many ways gaps may occur between teacher expectation and the final student product, and the integration of writing and digital genres into writing classrooms can yield mixed results. With the hope of inspiring students to experience what McLellan (2006) describes as "deep and lasting power" (p. 30), in reality, educators and students alike may be challenged by conflicts extending between process and product. In short, it is possible to have an assignment that lives somewhat in a void in-between process and product as well as the desire to uphold the teaching of the written word while embracing the technological advancements of the twenty-first century.

\section{Non-fiction Storytelling}

Using digital stories in a storytelling class appeared logical; however, it was a more problematic environment for students than those in my research writing classes. This experimental community contained a cohort of thirty, first-year students co-enrolled in an introductory writing course, an introductory psychology course, and my social constructs course that examined broad issues of race, ethnicity, sexuality, and the like. Despite spending a semester reading 
young adult books that outlined first-person stories of personal struggles, triumphs, peer pressure, incarceration, addiction, and physical abuse while discussing and writing about their connections to the reading material, when it came to crafting their stories in a digital fashion, they shrunk away from the idea of seeing their own stories in ways outside of the traditional written page.

Despite my beliefs aligning with Hernández-Zamora and Zotzmann's (2014) argument that students encouraged to "express themselves in unconventional genre formats precedes their ability and willingness to try on culturally distant genres, particularly the expositoryargumentative academic writing" (p. 80), students raised a variety of issues before the stories were due. The process was introduced the week after mid-term and addressed throughout the remaining eight weeks of the course both through in-class time and optional office hours. Likewise, they kept personal response journals regarding connections they made among themselves and others' stories. It seemed that creating the final project would have been a seamless and culminating event, but that did not always end up being the case.

This course brought to light not only the aforementioned lack of technology skills, but another type of digital discord regarding the public nature of videos. Despite hearing about, and seeing endless student posts that divulged a variety of personal information, students were reluctant to participate in the perceived permanency of their videos. As an officer on our student conduct board, I have witnessed a variety of inappropriate online content, from sexting to scathing commentary against fellow students or the school. Repeated evidence indicates that the digital generation is open to sharing intimate details of their lives on the plethora of social media platforms available. However, as the end of the semester loomed closer, students voiced concerns about the stories being "too personal" or "invasive," even though videos were made "public" only to their classmates. Furthermore, although many conversations circled around issues of privacy and selecting content appropriate for the "public audience" that consisted of their classroom peers, in the end, they were scared of being vulnerable, despite some very open, poignant, and sometimes emotional stories shared during classroom discussions.

The final products were varied. Obviously, some authentic digital stories were submitted, but some students chose to record themselves telling their stories that centered on a specific theme, thus bypassing the requirement to include a variety of images and music. One student recorded himself performing a rap song that he wrote. Others selected software programs that eliminated all personal representation, where the story was created through choreographed and application-generated animation. However, I still witnessed surprising connections. Students felt this vulnerability demonstrated an audience's awareness and the potential for longevity of committing content to a public platform. The mere fact that they were in an uncomfortable situation where decisions had to be made about their learning brought about valuable critical thinking. Even the products that were linked to application-generated animation demonstrated the time and effort it took to plan, outline, write scripts, and produce a final product; this sequence spoke to both the need to partake in writing-oriented activities as they related to the video production.

When I offer this course again, the digital stories will be integrated throughout the course instead of only being applied in the second half. Additionally, more discussion at the start of the project regarding content, as opposed to digital/technical requirements, will occur so that there is more time to address, discuss, and solve the concerns voiced by this class much too late into the course. Although I am always prepared for students' concerns over the technical aspects, discussed later, I was not prepared for their conservative nature regarding the sharing of their personal stories, especially after having participated in a three-course endeavor where their own and others' personal stories anchored the community experience. It may also be helpful to investigate the difference between a first-year and a second-year student in terms of their confidence levels, intellectual development, and other factors that account for differences in their products from those in the research writing course. 


\section{Research Writing}

Ironically, implementing the digital stories in a research class, which felt like a more considerable stretch, yielded more substantial results over an extended period. Upon my original classroom implementation several years ago, one concern with digital stories questioned how students might implement research findings in ways deemed "creative." What prevented students from merely reading the research paper and pulling together some random photographs?

This second-year research class that emphasizes secondary research data collection and information literacy skills is thematically based upon instructors' preferences; however, I have often allowed the class to select the theme and, over time, themes have examined the role of higher education in our current society, conspiracy theories, social media marketing, and service-learning/civic engagement. Within all of the themes, the products have been consistently robust, integrative, creative, and unique in their final digital forms. I offered a similar amount of preparation as was offered to the storytelling cohort, but the research students were sophomores as opposed to first-year students, and likely they were less intimidated by the content. They were not putting their personal "selves" in a potentially permanent venue, which was counter-intuitive to my original expectations. I initially thought students would feel more comfortable sharing their stories without requiring an expanded level of secondary and primary research.

Despite their comfort with the course material, there were still significant disconnects that demonstrated the accuracy of digital native research. Although they echoed, to a minor degree, the concerns of the storytelling students regarding the public disclosure of their work, the lack of technological skills became evident. Opposed to the storytelling digital stories, where the video emphasis was on personal photos and videos, the digital stories in this class had a more robust requirement of integrating secondary research. Students were repeatedly challenged with downloading third-party content, editing that content, and working with the video software to consolidate, order, time, narrate, and, ultimately, record the final product. So as not to lose classroom time unexpectedly, I posted instructional YouTube video links, handouts, examples, and guidelines to aid in their technological challenges as well as offered independent office hours that resulted in small group workshops that addressed only the technical elements of video production.

The research stories frequently wove together ethos, pathos, and logos in intriguing ways. Because the students were creating the final narrative, they emphasized the information they determined of most importance to construct their position. Likewise, they selected music's unique options to create a specific tone for the project - contemplative, upbeat, angry, and the like. The use of the visuals was robust as well. Some students captured original photos while others created original video. Others blended unique collections of online material, obviously taking care to source, or document, any materials that were not their original creations. Students benefited from practical conversations regarding technology implementation and application, while critical decision-making regarding product content remained at the forefront of in-class conversations and peer response sessions. Even the sharing of stories was positive as students applauded and commented on each other's final digital stories after the course.

\section{Classroom Implementation}

The lack of student preparation or lack of technological literacy should not dissuade teachers from using digital stories; if anything, it should encourage teachers to integrate digital stories as a benchmark within their curriculum for any of the outcomes listed above. Furthermore, I would argue that as instructors determine their purposes for digital story implementation, additional benefits outside of the ones I have outlined are likely to emerge. Like all new endeavors, time, patience, and the ability to experiment and revise should anchor the projects. 


\title{
Best Practices
}

As a result of teaching digital stories in the classroom for nearly seven years, and within different types of writing courses, the following insights are offered.

Introduce the assignment early in the term and revisit often.

Make sure the digital story integrates into the course curriculum instead of feeling like a "final exam" or an add-on towards the end of the term.

Offer examples, often readily available on YouTube or other video streaming sites.

\begin{abstract}
Avoid rubrics.
Ironically, when students asked for more definite guidelines, checklists, or rubrics, the stories became less dynamic as they started working to please the teacher instead of working towards content delivery in creative ways. Consider grading holistically.
\end{abstract}

Allow workshopping time.

Whether carving out class time or offering some workshop time during office hours, encouraging students to solicit feedback from their peers often encourages an earlier start.

Reach out to information technology (IT) resources on campus.

Often, there are IT students and campus departments that would love to be involved by offering workshops, resources, and suggestions.

Be clear in foundational expectations.

Create a handout that outlines the specifics of length ( 4 to 5 minutes is best) and content (i.e., secondary research, music, personal narration, video clips, web resources, personal photography, and the like).

Discuss the intersection between digital stories and traditional writing assignments.

Offer brainstorming sessions where students link images and music to ethos is helpful.

Be public with products.

Suggest a platform where students can view, critique, and discuss each other's videos.

Address appropriate documentation

Emphasize appropriate documentation of sources, including visuals and non-original videos; classroom conversations about appropriate sourcing are critical.

Reduce the length of the videos

Although videos can be a variety of lengths, $4-5$ minutes generally work best, especially in research stories. It is long enough to evolve and develop meaningful content without losing the audience's attention.

\section{Conclusion}

Regardless of the literacies necessary for the twenty-first century learner, whether digital, global, technological, visual, or informational, digital stories offer a full breadth of possibilities. In short, integrating multimodal and digital projects into the classroom, especially one focused on writing, can yield a plethora of benefits; however, assuming students possess the skills necessary for successful projects is often a faculty member's first error. Consequently, teachers must think about the final product they desire and the course outcomes they want their students to achieve; however, they need to think about the digital integration leading up to that project. Assuming a particular skill set based solely on students' generational upbringings often leads to poor results and significant frustration from both sides of the desk. Therefore, planning sufficient time for content development as well as for digital skills acquisition is essential. 


\section{References}

Akcayir, M., Dündar, H., \& Akcayir, G. (2016). What makes you a digital native? Is it enough to be born after 1980? Computers in Human Behavior, 60, 435-440. https://doi.org/10.1016/i.chb.2016.02.089

Bennett, S., \& Maton, K. (2010). Beyond the 'digital natives' debate: Towards a more nuanced understanding of students' technology experiences. Journal of Computer Assisted Learning, 26(5), 321-331. https://doi.org/10.1111/.1365-2729.2010.00360.x

Dreon, O., Kerper, R. M., \& Landis, J. (2011). Digital storytelling: A tool for teaching and learning in the YouTube Generation. Middle School Journal, 42(5), 4-10. https://doi.org/10.1080/00940771.2011.11461777

George, D. (2002). From analysis to design: Visual communication in the teaching of writing. College Composition and Communication, 54(1), 11-39. https://www.jstor.org/stable/1512100

Gilchrest, M. J. (2018). The Ground Beneath Our Feet: A Multi-Sited Analysis of Multimodal Composition. [Doctoral dissertation, University of lowa]. https://doi.org/10.17077/etd.c1uqk3q9

Harris, K. (2017, January 31). Digital literacy: the missing piece for Adult ESL learners. Oxford University Press English Language Teaching Global Blog. https://oupeltglobalblog.com/2017/01/31/digital-literacy-the-missing-piece-for-adultesl-learners/

Hernández-Zamora, G., \& Zotzmann, K. (2014). Digital literacy as a tool for self-authoring: Teaching reluctant student writers through "redesign". Journal of Global Literacies, Technologies, and Emerging Pedagogies, 2(2), 77-99.

http://www.joglep.com/files/4613/9629/4690/Digital literacy Final.pdf

Hull, G. A. (2003). At last: Youth culture and digital media: new literacies for new times. Research in the Teaching of English, 38(2), 229-233.

https://www.jstor.org/stable/40171638

McLellan, H. (2006). Digital storytelling: Bridging old and new. Educational Technology, 46(5), 26-31. https://www.jstor.org/stable/44429328

Ohler, J. (2006). The world of digital storytelling. Educational Leadership, 63(4), 44-47.

Oskoz, A., \& Elola, I. (2014). Integrating digital stories in the writing class: Toward a 21 $1^{\text {st-century }}$ literacy. In J.P. Guikema \& L. Williams (Eds.), Digital Literacies in Foreign and Second Language Education (pp. 179-200). Calico.

Porter, B. (2006). Beyond words: The craftsmanship of digital products. Learning and Leading with Technology, 33(8), 28-31.

Prensky, M. (2001). Digital natives, digital immigrants part 1. On the Horizon, 9(5), 1-6. https://doi.org/10.1108/10748120110424816

Prensky, M. (2004). The emerging online life of the digital native: What they do differently because of technology, and how they do it. Retrieved December 6, 2020 from http://www.marcprensky.com/writing/Prensky-

The Emerging Online Life of the Digital Native-03.pdf.

Robin, B. R. (2016). The power of digital storytelling to support teaching and learning. Digital Education Review, 30, 17-29. https://revistes.ub.edu/index.php/der/article/view/16104 
Rosen, L. (2010). Rewired: Understanding the iGeneration and the way they learn. Palgrave Macmillan.

Smith, E. E. (2012). The digital native debate in higher education: A comparative analysis of recent literature. Canadian Journal of Learning and Teaching, 38(3). https://doi.org/10.21432/T2F302

Strassman, B. K., \& O'Dell, K. (2012). Using open captions to revise writing in digital stories composed by d/Deaf and hard of hearing students. American Annals of the Deaf, 157(4), 340-357. https://www.jstor.org/stable/26234849

Thompson, P. (2013). The digital natives as learners: Technology use patterns and approaches to learning. Computers and Education, 65, 12-33. https://doi.org/10.1016/i.compedu.2012.12.022

Westman, P. J. (2012). "Playing with the team": The development of communities of practice in a digital storytelling project. Digital Education Review, 22, 92-100. 